\title{
Development of Simulation Model of Chloride Ion Transportation in Cracked Concrete
}

\author{
Ema Kato $^{1}$, Yoshitaka Kato ${ }^{2}$ and Taketo Uomoto $^{3}$
}

Received 9 June 2004, accepted 3 September 2004

\begin{abstract}
Chloride-induced deterioration is the most important deterioration phenomenon in reinforced concrete structures in marine environments. When a crack occurs in cover concrete, it may initiate and accelerate corrosion of steel reinforcements embedded in the concrete. The performance of the reinforced concrete structure may subsequently decrease even in the early stage of its service life. With the aim to clarify the mechanism of chloride-induced deterioration, this paper reports the results of experimental investigation on chloride ion transportation in cracked concrete and proposes a simulation model for chloride ion transportation in cracked concrete. The zone affected by cracking was treated as the exposed surface of concrete in the proposed model, where chloride transportation was assumed to be governed by the concentration of the chloride ion solution in the crack. In addition, the effects of the crack width and an apparent diffusion coefficient through the cracks on chloride ion transportation were numerically investigated and the applicability of the proposed model was discussed.
\end{abstract}

\section{Introduction}

When reinforced concrete structures are built in marine environments, an important deterioration phenomenon that must be taken into account is corrosion of steel reinforcements due to chloride ions. Corrosion of a steel reinforcement may decrease its cross-sectional area and deteriorate the bond between the steel reinforcement and concrete, which subsequently leads to degradation of the performance of the reinforced concrete structure.

In general, the penetration of factors causing deterioration such as chloride ions, oxygen, and water, into concrete is governed by the quality of the cover concrete. Furthermore, when a crack occurs in the cover concrete, the corrosion of the steel reinforcement may be accelerated because the deterioration causing factors can pass through the crack. In addition, according to Okada et al, 1979, and Otsuki et al, 1998, macro-cell corrosion can easily occur in the vicinity of cracks. Therefore, there is no doubt that cracks in the cover concrete greatly affect the durability of reinforced concrete structures. However, the characteristics of chloride ion transportation in cracked concrete have not yet been made clear. This paper reports the results of experimental investigation on chloride ion transportation in cracked concrete. Based on

${ }^{1}$ Researcher, Structural Mechanics Division, Port and Airport Research Institute, Japan.

E-mail:katoh-e@pari.go.jp

${ }^{2}$ Assistant professor, International Center for Urban Safety Engineering, Institute of Industrial Science, University of Tokyo, Japan.

${ }^{3}$ Professor, International Center for Urban Safety Engineering, Institute of Industrial Science, University of Tokyo, Japan. these experimental results, a simulation model for chloride ion transportation in cracked concrete is proposed.

\section{Property of chloride lon transportation in cracked concrete}

\subsection{Experimental procedure}

Table 1 lists the mix proportions of the concrete employed as test specimens. The initial chloride content was 0.01 wt. \% of cement. Figure 1 shows the geometry of the specimens. The specimens had a rectangular cross section of $70 \mathrm{~mm}(\mathrm{~W}) \times 120 \mathrm{~mm}(\mathrm{H})$, and their total length was $380 \mathrm{~mm}$. Three deformed steel bars of $10 \mathrm{~mm}$ in diameter were embedded longitudinally in the specimens, whose cover depths were fixed to 30,60 , and 90 $\mathrm{mm}$ from the exposed surface.

After undergoing curing in water for 28 days, the specimens were subjected to 4-point loads to generate a flexural crack. The compressive strengths of $\mathrm{W} / \mathrm{C}=0.39$ and $\mathrm{W} / \mathrm{C}=0.55$ concretes at cracking were $57.4 \mathrm{MPa}$ and 41.0 $\mathrm{MPa}$, respectively. After the load application, the widths of the cracks were measured at 7 points on the bottom surface of each specimen by microscope and the depths of the crack at the side surfaces of each specimen were measured by micrometer. In order to control the penetration of chloride ions into concrete, all surfaces except the bottom surface of the specimens were coated with epoxy. To simplify the phenomenon of chloride ion penetration through the crack, the specimens with a slit in

Table 1 Mix proportions of concrete.

\begin{tabular}{|c|c|c|c|c|c|c|c|}
\hline \multirow{2}{*}{$\mathrm{G}_{\max }$} & \multirow{2}{*}{$\mathrm{W} / \mathrm{C}$} & \multirow{2}{*}{$\mathrm{s} / \mathrm{a}$} & \multicolumn{5}{|c|}{ Unit content $\left(\mathrm{kg} / \mathrm{m}^{3}\right)$} \\
\hline & & & $\mathrm{W}$ & $\mathrm{C}$ & $\mathrm{S}$ & $\mathrm{G}$ & Ad. \\
\hline 20 & 0.39 & 0.42 & 177 & 454 & 720 & 1016 & 4.99 \\
\hline 20 & 0.55 & 0.46 & 166 & 304 & 857 & 1016 & 2.43 \\
\hline
\end{tabular}




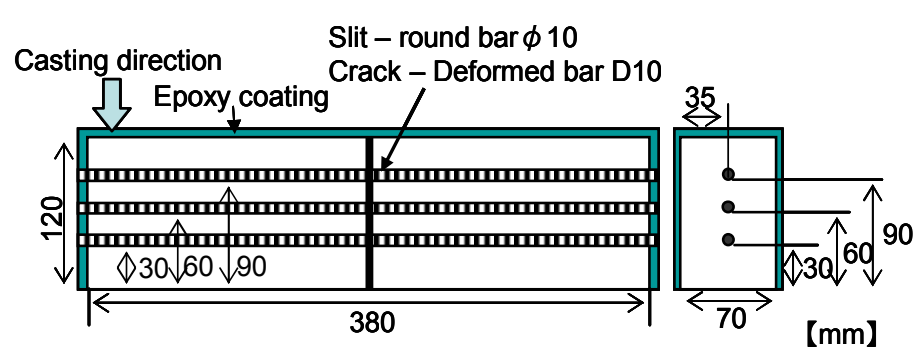

Fig.1 Specimen.

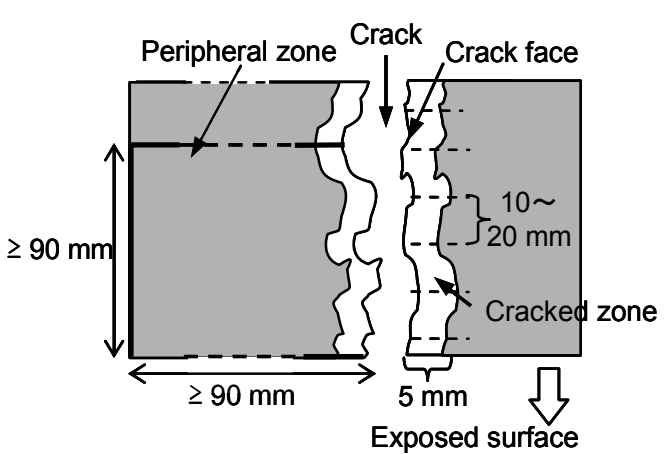

Fig.2 Sampling for measurement. their midspan were also made with the same geometry as the specimens without such a slit. The length and width of the slit were $120 \mathrm{~mm}$ and $0.20 \mathrm{~mm}$, respectively, and were confirmed to be kept constant during the test. All the surfaces of the slit specimens except the bottom surface were coated with epoxy. Three round bars rather than deformed bars were embedded in the slit specimens for simplification purposes.

All the specimens were then subjected to accelerated penetration of chloride ions for 91 days either through a wet test or through a cyclic drying-wetting test. In the wet test, specimens were submerged in a sodium chloride solution $(3.0 \% \mathrm{NaCl})$. Each cycle of the drying-wetting test consisted in wetting for 1 day through immersion in a sodium chloride solution $(3.0 \% \mathrm{NaCl})$ and drying for 6 days at $60 \%$ relative humidity. In both tests, the environmental temperature was kept constant at $40^{\circ} \mathrm{C}$ for accelerating the transportation of chloride ions.

After the accelerated penetration of chloride ions, concrete samples were taken from each specimen for measuring the chloride ion contents. In this paper, the cracked zone and its peripheral zone were defined as shown in Fig. 2. The thickness of the cracked zone was 5 $\mathrm{mm}$ on each side from the crack face, based on the roughness of the crack face and the average particle size of the aggregate. The peripheral zone was approximately $90 \mathrm{~mm}$ thick on each side from the crack face including the cracked zone. Concrete samples were taken from the cracked zone at intervals of 10 to $20 \mathrm{~mm}$ and then milled into powder samples. After the powder samples were dissolved, the chloride content at each sampling point was measured based on the test method of the Japan Concrete Institute (1987). An Electron Probe Micro Analyzer was used to measure the chloride content in the peripheral zone. Before the measurement, the surface of the concrete sample, which measured $90 \mathrm{~mm}$ by $90 \mathrm{~mm}$, was polished and coated with carbon.

\subsection{Chloride ion profiles in cracked concrete}

Figure 3 shows the chloride ion profiles in the cracked zone. In all the cases, the deeper from the crack face the sampling points was, the lesser the chloride content However, it was difficult to make clear the mechanism of chloride ion transportation in cracked concrete based only on these experimental results, because the crack in each test specimen became narrow during the test as presented in Table 2. Moreover, because the crack had a complicated shape (Goto, 1971), it was not possible to clearly identify the effects of the crack width and depth on chloride ion transportation. To clarify chloride ion transportation through the crack, chloride ion profiles in the cracked zone of the slit specimens were plotted, as shown in Fig. 3. The chloride content in the cracked zone also decreased with increases in the depth from the exposed surface. According to Iyoda et al (1998), the penetration depth of chloride ions from the crack face of concrete tended to be smaller than that from the exposed
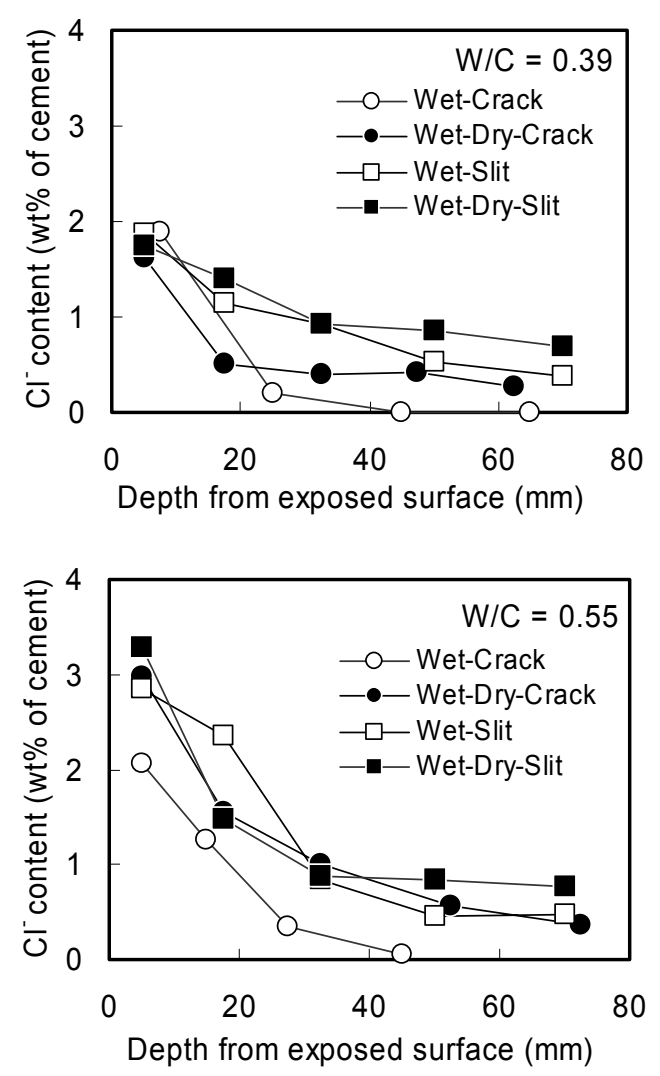

Fig. $3 \mathrm{Cl}^{-}$profiles in cracked zone. 
Table 2 Crack width before and after test.

\begin{tabular}{|l|l|l|l|l|}
\hline & \multicolumn{2}{|c|}{ Wet test } & \multicolumn{2}{c|}{ Wet-dry test } \\
\hline W/C & 0.39 & 0.55 & 0.39 & 0.55 \\
\hline Before $(\mathrm{mm})$ & 0.09 & 0.07 & 0.10 & 0.09 \\
\hline After(mm) & 0.03 & 0.04 & 0.06 & 0.07 \\
\hline
\end{tabular}

surface. From the experimental results, it can be considered that the concentration of chloride ion solution varies in the crack and has an influence on the chloride ion profile in the cracked zone. The reason for this is that, if the concentration of the chloride ion solution in the crack were uniform, the chloride contents in the cracked zone would not change along the depth from the exposed surface.

\section{Model of chloride ion transportation in cracked concrete in wet condition}

\subsection{Outline of model}

As mentioned earlier, the exact mechanism of chloride ion transportation in concrete has not been elucidated. The process of chloride ion transportation in concrete is considered to be governed by many factors such as diffusion, ionic interaction, water transportation, and chloride ion fixation. A simulation method for chloride ion transportation under various environments considering these factors was proposed for example by Maruya et al. (1998). However, this simulation model requires numerous experiments and inverse analyses. In this paper, a simple simulation model expressing chloride ion transportation in cracked concrete was proposed based on the experimental results and Fick's second law of diffusion with the apparent diffusion of chloride ions. Figure 4 shows the concept of the proposed model, which consists of the following 3 steps: 1) calculation of the chloride ion distribution in the crack, 2) calculation of the chloride content in the cracked zone and balance calculation on the total chloride content in the crack and in the cracked zone, and 3) calculation of the chloride ion content in the whole concrete. In calculation step 2), it was assumed that the chloride content in the cracked zone was gov-

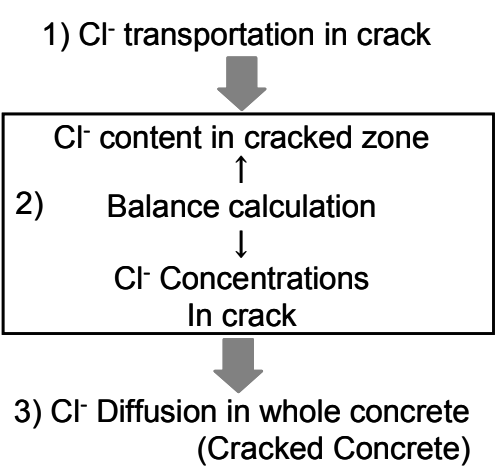

Fig. 4 Concept of proposed model. erned by the concentration of the chloride ion solution in the crack. In step 3), the cracked zone was treated as the boundary of the whole concrete. Using the calculated chloride content in the cracked zone as well as the experimental results of the apparent diffusion coefficient of the whole concrete and of the chloride content at the exposed surface of the concrete, chloride ion profiles in the whole cracked concrete were simulated. This simulation required the crack widths, the boundary chloride content, the apparent diffusion coefficient of chloride ions in the concrete, and the apparent diffusion coefficient of chloride ions through the crack. The apparent diffusion coefficient of chloride ions in the concrete and that through the crack were not changed according to the depth from the surface and the crack depth. The details of each step are described in the following sections.

\subsection{Chloride ion transportation through crack}

The analysis was started by calculating the distribution of the concentration of chloride ions in the crack. Since an apparent diffusion coefficient of chloride ions through a crack was required for the calculation, the following diffusion test was undertaken. Figure 5 shows the test pieces, which were made of concrete and steel. The mix proportions of the concrete for the concrete test piece were the same as those presented in Table 1. A crack was generated by applying a tension splitting load, and the average width of the resulting crack was obtained through measurement of the crack widths at ten points. Prior to the start of the diffusion test, the concrete test piece was immersed in water. The steel test piece had a slit with varied width as shown in Fig. 5. Since the face of slit was rather flat and smooth compared to that of crack in the concrete test piece, it was considered that the relationship between the apparent diffusion coefficient of chloride ion through the crack and the crack width became clearer. Figure 6 shows the setup of the diffusion test. During the test, environmental temperature was kept constant at $40{ }^{\circ} \mathrm{C}$. The diffusion test at $20{ }^{\circ} \mathrm{C}$ was additionally executed for the steel test piece.

The apparent diffusion coefficient of chloride ion through a crack was calculated by Eq. 1 (Buenfeld, 1984).

$$
J=\frac{V_{\mathrm{H}_{2} \mathrm{O}}}{A} \frac{d C_{\mathrm{H}_{2} \mathrm{O}}}{d t}=\frac{D_{c r}}{l}\left(C_{\mathrm{NaCl}}-C_{\mathrm{H}_{2} \mathrm{O}}\right)
$$

where, $J$ : flux of chloride ion, $l$ : thickness of test piece, $A$ : area of the crack or slit face, $t$ : time, $D_{c r}$ : apparent diffusion coefficient of chloride ion through the crack, and $C_{\mathrm{NaCl}}$ and $\mathrm{C}_{\mathrm{H} 2 \mathrm{O}}$ : chloride contents in respective cells.

Figure 7 shows the relationship between the crack width and the apparent diffusion coefficient of chloride ions through a crack, $D_{c r}\left(\mathrm{~cm}^{2} / \mathrm{s}\right) . D_{c r}$ increased with increases in the crack width and was almost constant when the crack width was approximately $0.075 \mathrm{~mm}$ or more. $D_{c r}$ of $\mathrm{W} / \mathrm{C}=0.55$ concrete was smaller than that of concrete with other $\mathrm{W} / \mathrm{C}$ ratios. The apparent diffusion coefficient of high $\mathrm{W} / \mathrm{C}$ concrete generally is larger than 


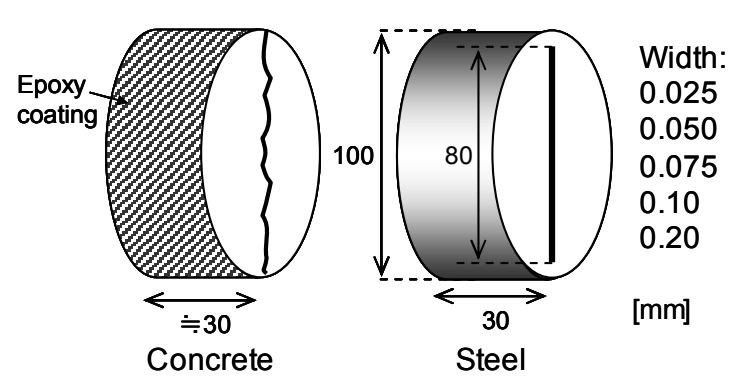

Fig. 5 Test piece.

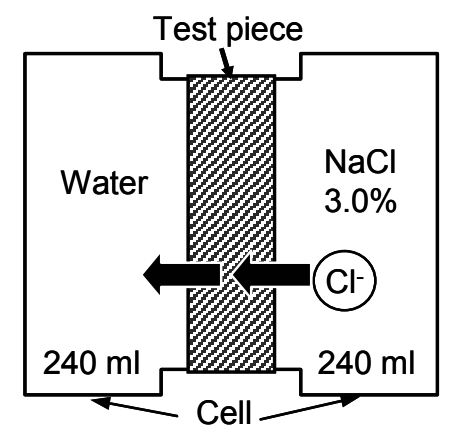

Fig. 6 Setup of diffusion test.

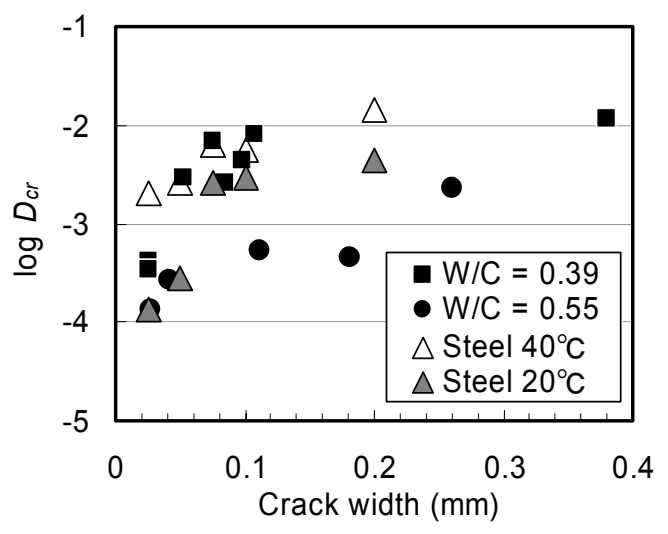

Fig. 7 Crack widths vs. $D_{c}$.

that of low W/C concrete. Therefore, chloride ion penetration through the crack to inside the concrete was considered to easily occur in $\mathrm{W} / \mathrm{C}=0.55$ concrete compared with $\mathrm{W} / \mathrm{C}=0.39$ concrete. Since such penetration as occurred in the concrete test pieces was not able to affect the apparent diffusion coefficient of the steel test pieces through a slit, $D_{c r}$ of the steel test pieces were used in the calculation of chloride ion transportation through the crack.

The distribution of the concentration of chloride ions in the crack was calculated through finite diffusion analysis with a crack model based on the crack width and the crack depth, the apparent diffusion coefficient through the crack $D_{c r}$ and the boundary chloride ion concentration of $3.0 \% \mathrm{NaCl}$.

\subsection{Setup of chloride content in the cracked zone and balance calculation of total amount of chloride content}

In order to treat the cracked zone as the boundary of the whole concrete, the chloride content at the exposed surface of concrete in $\mathrm{NaCl}$ solutions of various densities were experimentally investigated using the wet test. The test piece was a cylinder $100 \mathrm{~mm}$ in diameter and 100 $\mathrm{mm}$ in thickness. The mix proportions were the same as those presented in Table 1. The environmental temperature was controlled to be constant at $40^{\circ} \mathrm{C}$.

Figure 8 shows the experimental results obtained for the chloride content at the exposed surface. The chloride content at this location increased with increases in the concentration of chloride ions. The change in chloride content at the exposed surface over time was calculated by Eq. 2 (Masuda et al, 1988).

$$
C_{0}(t)=C^{*}\{1-\exp (-b t)\}
$$

where, $C_{0}(t)$ : chloride content at the exposed surface, $C^{*}$ and $b$ : experimental constants.

$C^{*}$ refers to the chloride content in the equilibrium state. $b$ depends on the period of time required for $C_{0}$ to become equal to $C^{*}$ and on $\mathrm{W} / \mathrm{C}$ of the concrete (Takeda et al, 2001). Therefore, it was possible to assume that $b$ was constant in concretes with the same $\mathrm{W} / \mathrm{C}$ ratio regardless of the concentration of the chloride ion solution. The calculated $C_{0}(t)$ figures are also shown in Fig. 8.
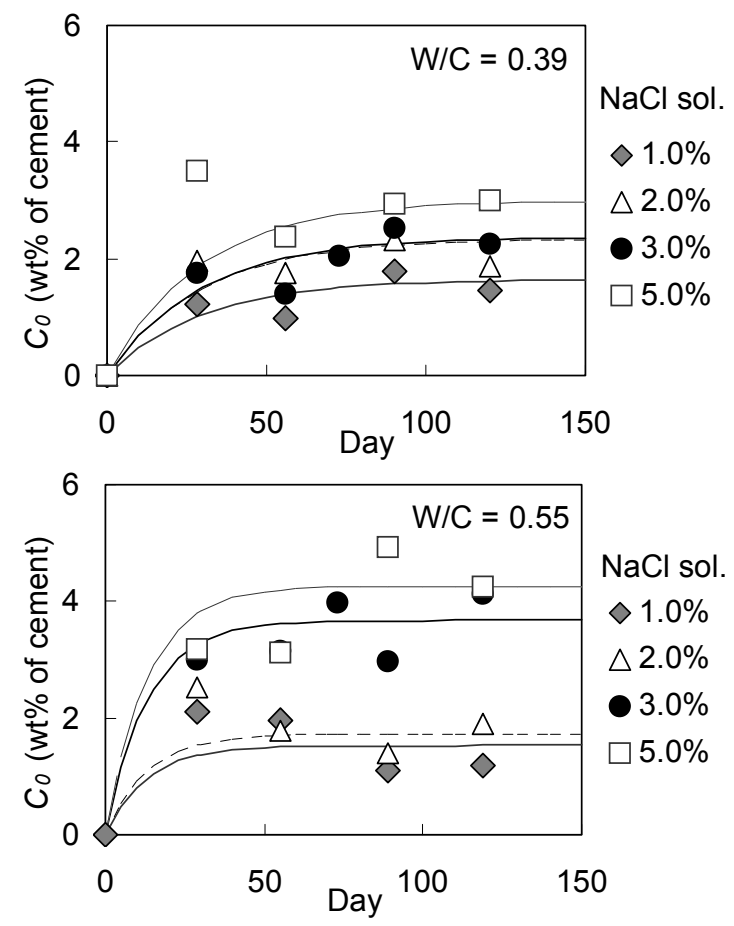

Fig. 8 Chloride content at exposed surface. 
The relationship between the concentration of chloride ion solution and $C^{*}$ is shown in Fig. 9, and can be approximated as Eq. 3 .

$$
C^{*}=\left(C_{c r}\right)^{1 / 2} a
$$

where, $C_{c r}$ : concentration of chloride ion solution and $a$ : experimental constant.

The chloride ion content in the cracked zone $C_{c o n}$ was calculated by the process shown in Fig. 10 with $D_{c r}$ and Eq. 2 and Eq. 3. $C_{c r}(t-\Delta t)$ refers to the concentration of the chloride ion solution in the crack at time $t$ - $\Delta t$. $C_{c r}(t-\Delta t)$ was obtained through diffusion analysis of the whole concrete shown as step 3) in Fig. 4 and Fig. 10 c). The details of that analysis are described in section 3.4 below. In Fig. 10, $C_{c r}$ ' $(t)$ refers to the concentration of the chloride ion solution in the crack at time $t$. $C_{c r}$ ' $(t)$ was obtained through diffusion analysis of chloride ion transportation through the crack (step 1) in Fig. 4). $\left(C_{c r}{ }^{\prime}(t)+C_{c r}(t-\Delta t)\right) / 2$ refers to the approximated average concentration of the chloride ion solution in the crack during $\Delta t$. Therefore, the chloride content in the cracked zone during $\Delta t$ can be referred to as $C_{0}\left(C_{c r}{ }^{\prime}(t)+\right.$ $\left.\left.C_{c r}(t-\Delta t)\right) / 2\right)$. When time $T$ was set for the balance calculation of the total amount of the chloride content in the cracked zone and in the crack, $C_{c o n}(t-\Delta t)$ could be treated as the chloride content at the surface of the concrete by using $T$ as shown in Eq. 4 (Fig. 10 b).

$$
\left.C_{c o n}(t-\Delta t)=C_{c o n}(T)=C_{0}\left(C_{c r}{ }^{\prime}(t)+C_{c r}(t-\Delta t)\right) / 2\right)\{1-\exp (-b(T))\}(4)
$$

$C_{c o n}(\mathrm{~T}+\Delta t)$ was also calculated by Eq. 4 . The chloride content in the cracked zone at $t C_{c o n}{ }^{\prime}(t)$ was obtained by balancing the total amount of chloride content in the cracked zone and in the crack.

\subsection{Chloride ion transportation in whole con- crete}

In the diffusion analysis of the whole concrete, apparent diffusion coefficient $D_{\text {con }}$ of uncracked concrete immersed in a $3.0 \% \mathrm{NaCl}$ solution and the chloride content at the exposed surface of that concrete were analyzed based on experimental results as shown in Eq. 5 and Eq. 6 (Crank, 1995). The results were then applied to the simulation of the chloride ion profile in the cracked concrete.

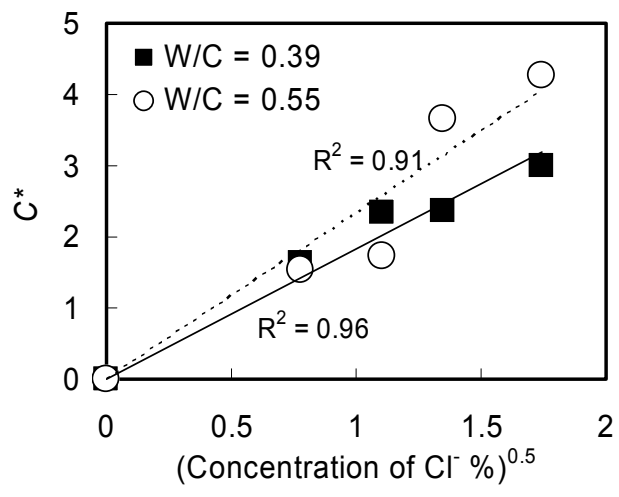

Fig. 9 Concentration of solution vs. $C^{*}$.

$$
\begin{aligned}
& {[\mathrm{W} / \mathrm{C}=0.39]} \\
& D_{c o n}=1.39 \times 10^{-7} \mathrm{~cm}^{2} / \mathrm{s}, C_{0}(t)=2.40\{1-\exp (0.034 t)\} \\
& {[\mathrm{W} / \mathrm{C}=0.55]} \\
& D_{\text {con }}=2.13 \times 10^{-7} \mathrm{~cm}^{2} / \mathrm{s}, C_{0}(t)=3.67\{1-\exp (0.076 t)\}
\end{aligned}
$$

\subsection{Verification of proposed model}

The chloride ion profiles in the cracked zone and in the whole concrete of the slit specimens after 91 days of exposure are shown in Fig. 11 and Fig. 12, respectively. The contour lines of experimental results in Fig. 12 were obtained by averaging the measurement data obtained with the Electron Probe Micro Analyzer in an area of 5 $\mathrm{mm} \times 5 \mathrm{~mm}$. In addition, the contour lines of the calculated results were obtained by averaging the calculated data in the same way. Since the apparent diffusion coefficient of the whole concrete of $\mathrm{W} / \mathrm{C}=0.39$ was smaller than that of the concrete of $\mathrm{W} / \mathrm{C}=0.55$, the penetration of chloride ions into concrete of $\mathrm{W} / \mathrm{C}=0.39$ is considered difficult. It was concluded that the proposed model is able to simulate the experimental result on chloride ion profiles in the wet condition, particularly in the cracked zone.

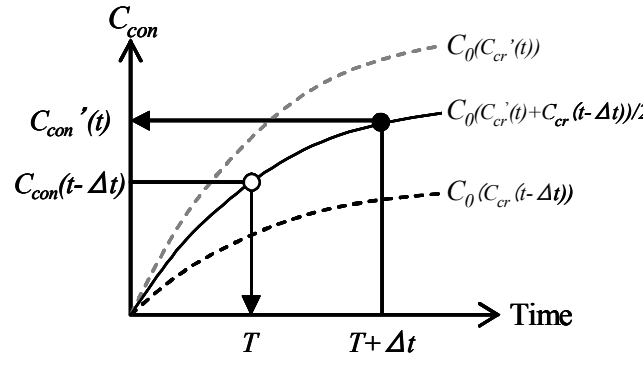

a) Setup of $C_{c o n}$

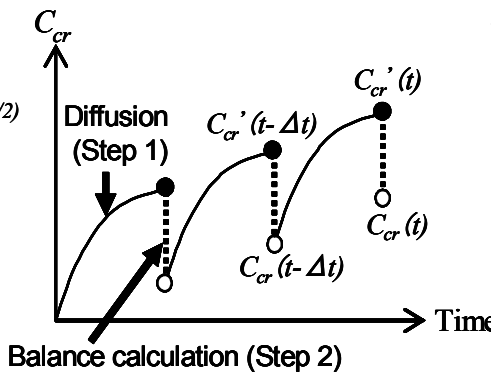

b) Image of change in $C_{c r}$

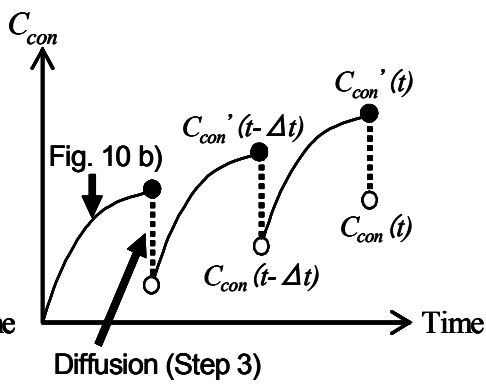

c) Image of change in $C_{\text {con }}$

Fig.10 Setup of $\mathrm{Cl}^{-}$content in cracked zone. 


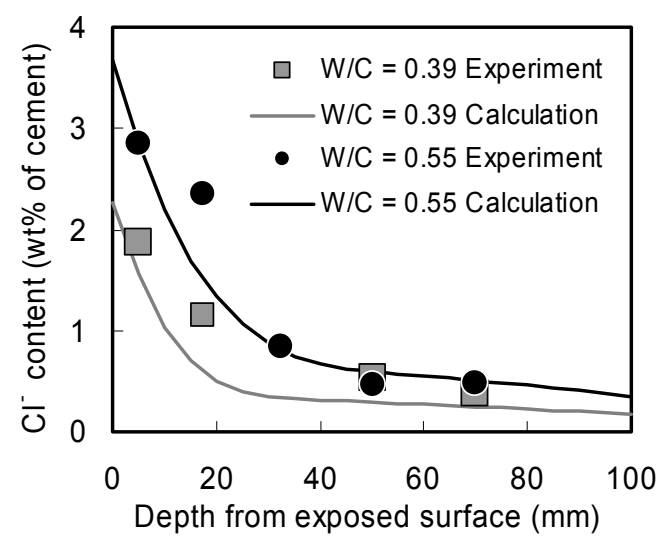

Fig. $11 \mathrm{Cl}^{-}$profile in cracked zone.

\section{Model of chloride ion transportation in cracked concrete in cyclic drying-wetting condition}

\subsection{Outline of model}

In the cyclic drying-wetting condition, chloride ion transportation in concrete seems more complex than in the wet condition. In this paper, a model based on the experimental results in the cyclic drying-wetting condi- tion and the diffusion theory is also proposed based on a similar concept mentioned earlier. Figure 13 shows the outline of the simulation model in the cyclic drying-wetting condition. It consists of the following 3 steps: 1) calculation of chloride ion transportation in wet condition, 2) setup of chloride content in the cracked zone in the cyclic drying-wetting condition, and 3) chloride ion transportation in the whole concrete model in the cyclic drying-wetting condition. Step 1) was conducted to calculate the average concentration of the chloride ion solution in the crack. Because the chloride ion content in the cracked zone was considered to be dependent on the concentration of the chloride ion solution in the wet condition, the chloride content in the cracked zone in the cyclic drying-wetting condition were calculated by using the average concentration in the crack. Chloride ion profiles in the cyclic drying-wetting condition were then simulated by using the chloride content in the cracked zone, the diffusion coefficient of the whole concrete and the chloride content at the exposed surface of the concrete in the cyclic drying-wetting condition.

\subsection{Setup of chloride content in cracked zone}

Figure 14 shows the setup of the chloride ion content in the cracked zone, $C_{c o n}(t)$. The chloride content in the cracked zone was calculated based on the average concentration of the chloride ion solution in the crack $C_{c r}(x)$.

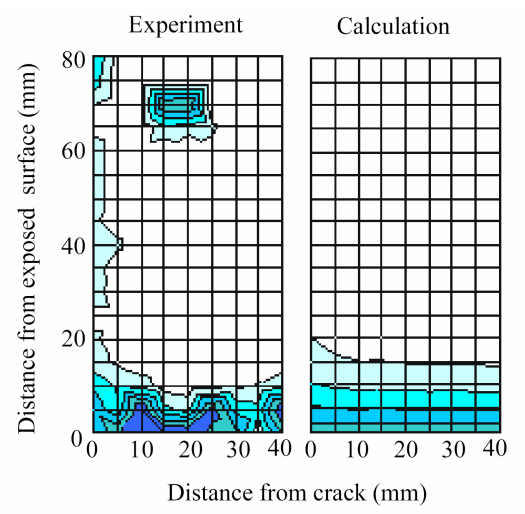

$\mathrm{W} / \mathrm{C}=0.39$

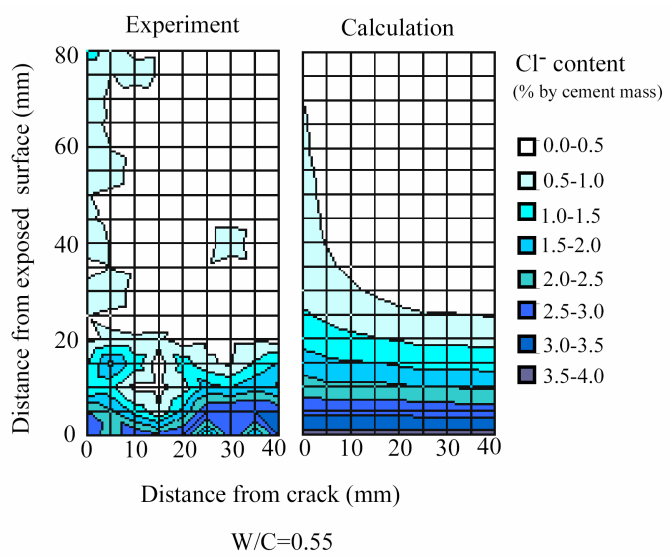

Fig. $12 \mathrm{Cl}^{-}$profiles in whole concrete.

1) Wet condition for 1 day $\rightarrow \mathrm{Cl}^{-}$concentrations in crack

2) Wet-dry condition for 7 days $\mathrm{Cl}^{-}$in cracked zone $\downarrow \uparrow$

$\mathrm{Cl}$ - Diffusion in whole concrete (Cracked concrete)

$\mathrm{Cl}^{-}$content in cracked zone (Next cycle)

Fig.13 Outline of cyclic drying-wetting condition.

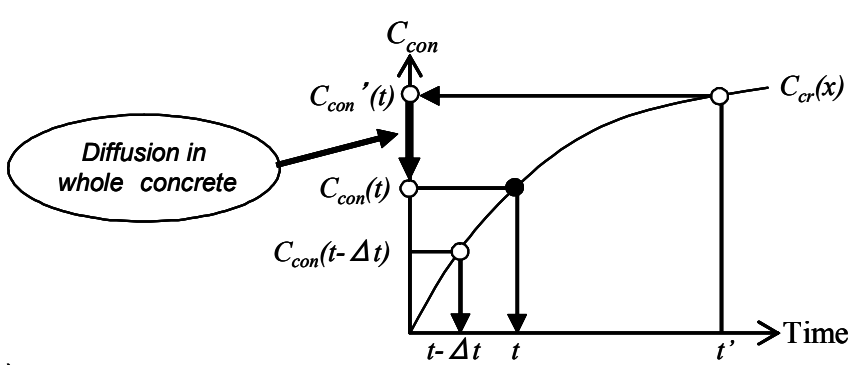

Fig.14 Setup of $\mathrm{Cl}^{-}$content in cracked zone. 
Describing the relationship between the concentration of the chloride ion solution and $C^{*}$ as Eq. 7 made it possible to describe the chloride content in the cracked zone $C_{c o n}{ }^{\prime}(t)$ as Eq. 8 by using $T$, which was set for the balance calculation of the total amount of the chloride content in the cracked zone and in the crack.

$$
\begin{aligned}
& C^{*}=\left(C_{c r}(x)\right)^{1 / 2} a \\
& C_{c o n}(t)=C^{*}\{1-\exp (-b T)\}
\end{aligned}
$$

The chloride ion content in the cracked zone at $t$, $C_{c o n}$ ' $(t)$, decreased because chloride ions diffused into the whole concrete. Using $C_{c o n}(t)$ as the chloride ion content in the cracked zone, the chloride content in the cracked zone at $t+\Delta t, C_{c o n}(t+\Delta t)$, was calculated by Eq. 8 with $C_{\text {con }}(t)$ as the initial condition.

\subsection{Chloride ion transportation in whole con- crete}

In the diffusion analysis of the whole concrete model, apparent diffusion coefficient $D_{\text {con }}$ of uncracked concrete in the cyclic drying-wetting condition and the chloride content at the exposed surface of the concrete were calculated using the following equations:

$$
\begin{aligned}
& {[\mathrm{W} / \mathrm{C}=0.39]} \\
& D_{c o n}=8.10 \times 10^{-8} \mathrm{~cm}^{2} / \mathrm{s}, C_{0}(t)=1.67\{1-\exp (0.13 t)\} \\
& {[\mathrm{W} / \mathrm{C}=0.55]} \\
& D_{c o n}=1.96 \times 10^{-7} \mathrm{~cm}^{2} / \mathrm{s}, C_{0}(t)=2.75\{1-\exp (0.15 t)\}
\end{aligned}
$$

Applying $C^{*}$ and $b$ of each case to Eq. 3, $a$ of each case were approximately defined. It was then possible to calculate the chloride content in the cracked zone.

\subsection{Verification of proposed model}

The chloride ion profiles in the cracked zone of the slit specimen after 91 days of exposure are shown in Fig. 15. In the cyclic drying-wetting condition, it was also concluded that the experimental results of the chloride ion profiles were accurately evaluated by the proposed model. The calculated chloride contents were smaller

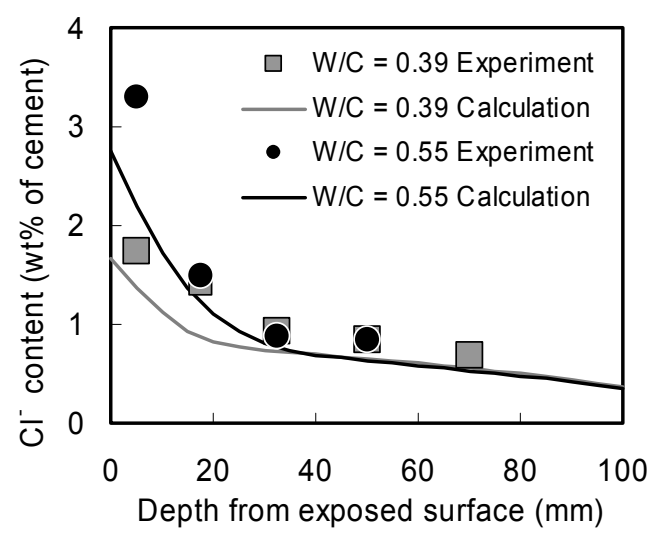

Fig. 15 Chloride ion profiles in cracked zone. than those of the experimental results. In this paper, $C^{*}$ and $b$ in Eq. 7 and Eq. 8 were calculated from the chloride profile of the short-term experiment. Swamy et al (1994) concluded that a longer time was required to make $C^{*}$ and $b$ stable in splash and tidal zones than in submerged zones. Setting $C^{*}$ and $b$, which had an influenced on $a$ in Eq. 3, was important to improve the accuracy of the proposed model.

\section{Studies on application of proposed model}

\subsection{Effect of cracks on chloride ion transporta- tion}

It is possible to evaluate chloride ion transportation in cracked concrete by the proposed models described earlier only if the crack width, chloride ion contents at the exposed surface ( $C^{*}$ and $b$ in Eq. 2), apparent diffusion coefficient of chloride ions in concrete $D_{c o n}$, apparent diffusion coefficient of chloride ions through crack $D_{c r}$, and the environmental condition (wet or cyclic drying-wetting condition) are precisely obtained.

In actual RC structures, $C^{*}, b$ and $D_{c o n}$ can be evaluated by the chloride ion profiles of the whole concrete. The crack width at the surface of the concrete can be measured. While $D_{c r}$ can also be evaluated by the diffusion test as shown in Fig. 6, it is difficult to obtain the $D_{c r}$ value at each crack width and at each environmental temperature. Using the proposed model, the influences of crack widths and $D_{c r}$ on chloride ion transportation in cracked concrete were analytically investigated in the following sections.

\section{a) Effect of crack width on chloride ion transporta- tion in cracked concrete}

Figure 16 shows the calculated relationship between the crack width and chloride content in the cracked zone. In the calculation, $D_{c r}$ was set to the diffusion coefficient obtained by the test of the steel test piece, while $C^{*}, b$ and

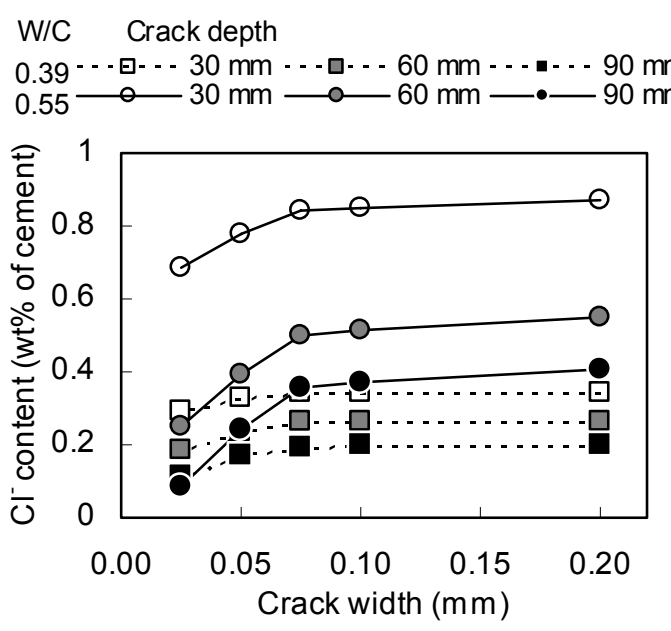

Fig. 16 Crack width vs. $\mathrm{Cl}^{-}$contents in cracked zone. 
$D_{\text {con }}$ were set as Eq. 7 and Eq. 8. The chloride content in the cracked zone increased with increases in the crack width up to $0.075 \mathrm{~mm}$. When the crack width was larger than $0.075 \mathrm{~mm}$, the chloride content in the cracked zone became constant up to the crack width of $1.0 \mathrm{~mm}$ in the simulation. This result was more remarkable in $\mathrm{W} / \mathrm{C}=$ 0.55 concrete compared with $\mathrm{W} / \mathrm{C}=0.39$ concrete. These results suggest that the chloride content in the cracked zone may depend on the crack width governing the chloride ion supply and the diffusion coefficient of chloride ions in the whole concrete, $D_{c o n}$, which governs the chloride ion consumption. In addition, the results seem to indicate that the crack width governs the chloride content in the cracked zone when chloride ions are consumed faster than they are supplied.

\section{b) Effect of $D_{c r}$ on chloride ion transportation in cracked concrete}

Figure 17 shows the calculated relationship between the depth from the crack face and the chloride ion profiles in the cover concrete. In the calculation, the crack width was fixed to $0.20 \mathrm{~mm}$, while $D_{c r}$ was set to $D_{l}(=1.45 \times$ $10^{-2} \mathrm{~cm}^{2} / \mathrm{s}$, which was the diffusion coefficient of the steel test piece with a crack width of $0.20 \mathrm{~mm}$ ) or $D_{2}$ (= $2.02 \times 10^{-3} \mathrm{~cm}^{2} / \mathrm{s}$, which was the diffusion coefficient of the test piece with a crack width of $0.025 \mathrm{~mm}) . C^{*}, b$ and $D_{c o n}$ were set as Eq. 7 and Eq. 8. The difference in the calculated results of D1 and D2 increased with decreases in the depth from the crack face. It also increased with increases in W/C and Dcr. These calculated results suggest that considering the effect of Dcr on the chloride ion profiles in cracked concrete may be important to evaluate chloride ion transportation in the cracked concrete. Furthermore, these results suggest that safety assessment of chloride ion transportation is made possible by the application of D1.

\subsection{Application of proposed model}

The proposed model described earlier was able to evaluate chloride ion transportation in cracked concrete only if crack widths, the boundary chloride contents $\left(C^{*}\right.$ and $b$ in Eq. 2), and the diffusion coefficient of chloride

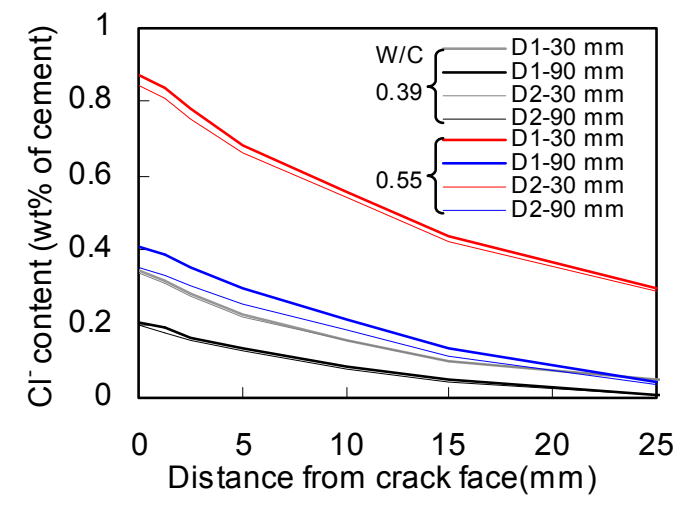

Fig. 17 Effects of diffusion coefficient of $\mathrm{Cl}^{-}$in crack. ions in the concrete, $D_{c o n}$, were precisely obtained. $C^{*}, b$ and $D_{c o n}$ in both wet and cyclic drying-wetting conditions are required to calculate the chloride ion profiles in the cyclic drying-wetting condition; however, it is impossible to investigate $C^{*}, b$ and $D_{c o n}$ in both the wet and cyclic drying-wetting conditions. In this section, the proposed model was applied to simulate the chloride ion profile in concrete having different mix proportions from that of the earlier tests and in the exposed condition, while $C^{*}, b$ and $D_{c o n}$ of that concrete in the wet condition were not obtained.

\section{a) Specimens}

Table 3 lists the mix proportions of the concrete for the test specimens. The initial chloride content was $0.007 \%$ weight of cement. Figure 18 shows the outline of the specimens. After curing, a crack of $0.09 \mathrm{~mm}$ in width was generated by the loading, while compressive strength was $31.7 \mathrm{MPa}$. The specimens were exposed to cyclic drying-wetting repetition for 28 days or 91 days. One cycle of cyclic drying-wetting repetition consisted in wetting in a sodium chloride solution for 4 days and drying in air with $60 \%$ relative humidity for 3 days. The environmental temperature was kept constant at $20^{\circ} \mathrm{C}$.

\section{b) Conditions of calculation}

$D_{c o n}, C_{0}(t)$ and $C^{*}$ in cyclic drying-wetting condition were calculated from the chloride profiles.

$$
\begin{aligned}
& D_{c o n}=3.36 \times 10^{-7} \mathrm{~cm}^{2} / \mathrm{s}, C_{0}(t)=3.98\{1-\exp (0.050 t)\} \\
& C^{*}=\left(C_{c r}\right)^{1 / 2} \times 2.95
\end{aligned}
$$

$D_{c o n}, b$ in $C_{0}(t)$ (according to Eq. 2) and $a$ in $C^{*}$ (according to Eq. 3) in the wet condition were calculated as shown in Fig. 19 by using experimental results of W/C = 0.39 and 0.55 shown in Eq. 5 and Eq. 6. Since those parameters are considered to depend on the internal pore structure of the concrete, it could be assumed that W/C has a large influence on these parameters. In this specimen, one cycle of drying-wetting calculation for simulating the chloride ion profile consisted in wetting calculation for 4 days and cyclic drying-wetting calculation for 7 days.

\section{c) Verification}

The chloride ion profiles in the cracked zone and in the whole concrete at the age of 91 days are shown in Fig. 20 and Fig. 21, respectively. They were well simulated by the proposed model using simply estimated parameters $D_{c o n}, b$ and $a$ in the wet condition. These results suggest that the proposed model possibly evaluates chloride ion profiles in cracked concrete under wet and cyclic dry-

Table 3 Mix proportions of concrete.

\begin{tabular}{|c|c|c|c|c|c|c|c|}
\hline \multirow{2}{*}{$\mathrm{G}_{\max }$} & \multirow{2}{*}{$\mathrm{W} / \mathrm{C}$} & \multirow{2}{*}{$\mathrm{s} / \mathrm{a}$} & \multicolumn{5}{|c|}{ Unit content $\left(\mathrm{kg} / \mathrm{m}^{3}\right)$} \\
\cline { 4 - 8 } & & & $\mathrm{W}$ & $\mathrm{C}$ & $\mathrm{S}$ & $\mathrm{G}$ & $\mathrm{Ad}$. \\
\hline 20 & 0.60 & 0.49 & 161 & 268 & 897 & 974 & 0.80 \\
\hline
\end{tabular}




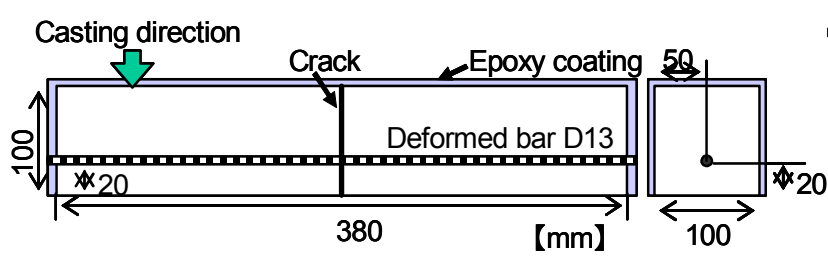

Fig.18 Specimen.

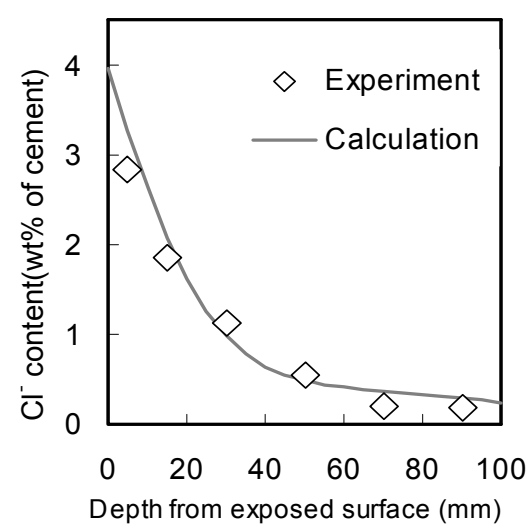

Fig.20 $\mathrm{Cl}^{-}$content in cracked zone.

ing-wetting conditions, when the environmental condition is treated as a periodic condition.

\section{Conclusions}

(1) The chloride content in the cracked zone decreased with increases in the depth from the exposed surface. The distribution of the concentration of the chloride ion solution in the crack was considered to have an influence on the chloride ion profile in the cracked zone

(2) A simplified simulation model for chloride ion transportation in cracked concrete was proposed. In the proposed model, the cracked zone was treated as the exposed surface of the concrete while considering the balance of the total amount of chloride in the cracked zone and in the crack.

(3) The chloride content in the cracked zone was found to depend on the crack width, which governs the chloride ion supply, and a diffusion coefficient of chloride ions in the whole concrete, which governs chloride ion consumption. In addition, the crack width governs the chloride content in the cracked zone when the chloride ion supply becomes smaller than chloride ion consumption. (4) The proposed model was able to simulate chloride ion profiles in cracked concrete under wet and periodic drying-wetting conditions only if the crack width, the chloride content at the exposed surface, and the diffusion coefficient of chloride ions in the whole concrete were
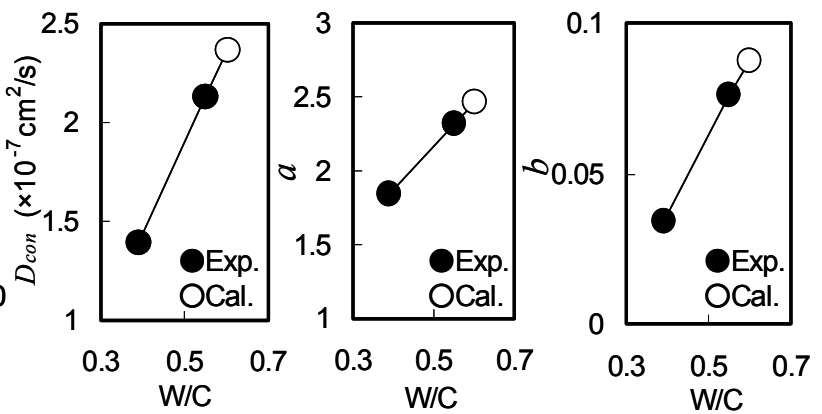

Fig.19 Calculation for $D_{c o n}, a$ and $b$.

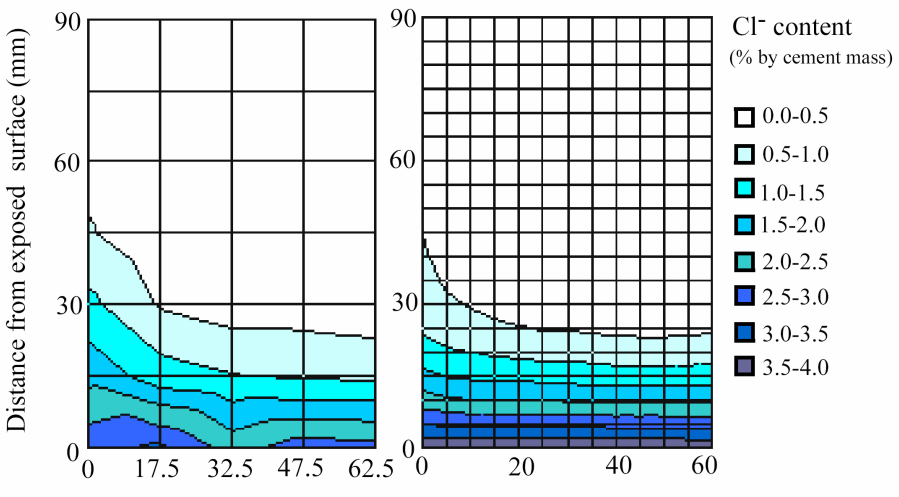

Distance from crack (mm)

Fig.21 $\mathrm{Cl}^{-}$profiles.

precisely obtained.

\section{Acknowledgement}

The authors would like to extend their appreciation to Dr. Hiroshi Yokota, Port and Airport Research Institute, for his valuable suggestions regarding this research.

\section{References}

Buenfeld, N. R. and Newman, J. B. (1987). "Examination of three methods for studying ion diffusion in cement pastes, mortars and concrete." Materials and Structures, 20 (115), 3-10.

Crank, J. (1995). "The Mathematics of Diffusion." Second Edition, Oxford Science Publications.

Goto, Y. (1971), "Cracks formed in concrete around deformed tension bars.” ACI Journal, 68 (4), 224-251.

Iyoda, T. and Uomoto, T. (1998). "Effect of existence of cracks in concrete on depth of chloride penetration." Journal of Institute of Industrial Science, University of Tokyo, 50 (10), 40-42, (in Japanese).

Japan Concrete Institute (1987). "Corrosion of Concrete Structures." Standards and Test Methods for Corrosion Protection (Guide), (in Japanese).

Maruya, T., Tangtermsirikul, S. and Matsuoka, Y. (1998). "Modeling of chloride ion movement in the surface layer of hardened concrete." Concrete Library of JSCE (32), 69-84. 
Masuda, Y., Tomozawa, F., Yasuda, M. and Hara, K. (1988). "An experimental study on chloride ion penetration into concrete." Proceedings of the Japan Concrete Institute, 10 (2), 493-498, (in Japanese).

Okada, K., Koyanagi, W. and Miyagawa, T. (1979). "Chloride corrosion of reinforcing steel in cracked concrete." Proceedings of JSCE (281), 75-87, (in Japanese).

Otsuki, N., Miyazato, S., Diola, N. B. and Suzuki, H. (2000). "Influences of bending crack and water-cement ratio on chloride-induced corrosion of main reinforcing bars and stirrups." ACI materials
Journal, 97 (4), 454-464.

Swamy, R. N., Hamada, H. and Laiw, J. C. (1994). “A critical evaluation of chloride penetration into concrete in marine environment." Proceedings of the International Conference on Corrosion and Corrosion Protection of Steel in Concrete, 1, 404-414.

Takeda, Y., Masuda, Y., Nakamura, S. and Kise, K. (2001). "Experimental study on penetration mechanism of chloride ions into cement paste." Proceedings of the Japan Concrete Institute, 23 (2), 505-510, (in Japanese). 